\title{
Fungos anemófilos de Manaus
}

\author{
Ozório José de Menezes Fonseca (*) \\ Lucia Alves Conceiçăo (")
}

\begin{abstract}
Resumo
São apresentados os resultados do levantamento dos fungos do ar da cidade de Manaus, Amazonas, coletados de setembro de 1975 a agosto de 1976, em dois locais da cidade. Os achados săo relacionados às variaçōes climatológicas anuais e comparados aos resultados de trabalhos similares realizados em outras cidades brasileiras.
\end{abstract}

\section{INTRODUÇÃo}

As condições climáticas nos trópicos favorecem a proliferação de fungos cujos esporos ou fragmentos hifais, ao serem levados para a atmosfera, vão se constituir em elementos anemófilos potencialmente alergizantes. Segundo Mendes (1972), as condições do clima brasileiro são favoráveis ao crescimento de fungos, podendo resultar altas coricentraçōes de esporos na atmosfera.

Gregory (1961) salienta que os fungos, como um grupo, são dotados de atributos que favorecem o seu estabelecimento e persistência no estado aerolizado. Seus esporos variam em diâmetro de menos de $1 \mu \mathrm{m}$ a mais de $10 \mu \mathrm{m}$ e são caracteristicamente resistentes a uma larga variação de temperatura, umidade relativa, dessecação e energia luminosa. Esses fatores, isolada ou associadamente, influenciam a viabilidade de células microbianas suspensas no meio aéreo.

Por outro lado, a existência de microrganismos no ar favorece a dispersão e disseminação de várias doenças, ao mesmo tempo em que podem estar associados à etiopatogenia das alergoses do trato respiratório.

No Brasil, até 1970, segundo Mendes \& Lacaz (1970), apenas oito cidades brasileiras haviam tido sua flora fúngica anemófila estudada: Belém, Recife, Belo Horizonte, Rio de Janeiro, São Paulo, Santos, Piracicaba e Porto
Alegre. Este trabalho inclui Manaus na relação, mas sugere que as floras polínica e bacteriológica deveriam ser, também, analisadas com a finalidade de estabelecer um mapa alergênico da cidade.

\section{MATERIAL E MÉTODOS}

O método utilizado foi o da exposição de placas de Petri de $13 \mathrm{~cm}$ de diâmetro, contendo 0 meio de Sabouraud-glicose-agar mais $250 \mathrm{mg}$ de Cloranfenicol (CEME) por litro de meio, durante 15 minutos, entre 10:30' e $11: 00 \mathrm{~h}$ da manhã, a mais ou menos $1,50 \mathrm{~m}$ do solo, semanalmente, em dois locais da cidade de Manaus.

As coletas foram feitas de setembro de 1975 a agosto de 1976. Os locais escolhidos foram: o "campus" do Instituto Nacional de Pesquisas da Amazônia (INPA), no lado leste da cidade, e a área atrás do Hospital de Moléstias Tropicais (HMT), no lado oeste da cidade. A escolha dos locais obedeceu a aspectos de ordem prática, em associação com a localização extrema dos dois pontos. No início do programa coletou-se em mais dois locais: centro da cidade e Reserva Florestal Ducke, no $\mathrm{km} 26$ da rodovia AM-010, porém, em novembro, esses locais foram abandonados por problemas de execução e os resultados não são demonstrados nesse trabalho.

As placas de Petri, após exposição, eram transportadas para o laboratório e incubadas a temperatura ambiente por sete dias, ao final dos quais se procedia o isolamento dos fungos em tubos de ensaio com o meio de Sabouraud simples para posterior identificação

Os fungos, mais facilmente reconhecíveis, foram identificados pelos aspectos macro e microscópicos, estes últimos através de lâminas coradas pelo lactofenol de Amann. Os cogumelos sobre os quais pairavam dúvidas

(`) - Instituto Nacional de Pesquisas da Amazônia, Manaus. 
eram cultivados em lâminas, fixados pelo formol e observados ao microscópio. As culturas que não apresentavam estruturas micromorfológicas que permitissem sua classificação, foram repicadas para outros meios. Após essas tentativas, as que ainda não evidenciavam estruturas para identificação foram registradas como "não identificados".

Os dados meteorológicos foram gentilmente cedidos pelo Departamento de Meteorologia, Estação de Manaus.

\section{RESULTADOS}

As Tabelas e Gráficos, seguintes, mostram os resultados obtidos.

TABELA 1 - Fungos isolados, por ordem de freqüência, durante 0 ano (setembro 75 - agosto 76).

Fungos

N. $\bullet$ de
Isolamentos

Cladosporium

Leveduras brancas

Penicillium

Aspergillus

Fusarium

Rhodotorula

Monilia

Curvularia

Trichoderma

Phialophora

Mucor

Cunninghamella

Pleiochaeta

Syncephalastrum

Cordaria

Acremonium

Pullularia

Helminthosporium

Acremoniella

Paecilomyces

Humicola

Nigrospora

Levedura preta

Rhizopus

Cephalosporium

Hyalodendron

Phoma

Pithomyces

Bispora

Não identificados

TOTAL (N)
$\%$

$\mathbf{N}$

$\begin{array}{rr}411 & 37,53 \\ 165 & 15,05 \\ 120 & 10,96 \\ 70 & 6,39 \\ 49 & 4,48 \\ 44 & 4,02 \\ 44 & 4,02 \\ 26 & 2,37 \\ 18 & 1,64 \\ 14 & 1,28 \\ 9 & 0,82 \\ 9 & 0,82 \\ 8 & 0,73 \\ 7 & 0,64 \\ 7 & 0,64 \\ 5 & 0,46 \\ 5 & 0,46 \\ 4 & 0,37 \\ 3 & 0,27 \\ 3 & 0,27 \\ 2 & 0,18 \\ 2 & 0,18 \\ 2 & 0,18 \\ 2 & 0,18 \\ 1 & 0,09 \\ 1 & 0,09 \\ 1 & 0,09 \\ 1 & 0,09 \\ 1 & 0,09 \\ 60 & 5,48\end{array}$

1095
TABELA 2- Freqüência de fungos isolados por número de exposições.

\section{Fungos}

Cladosporium

Leveduras brancas

Penicillium

47,12

Aspergillus

38,46

Rhodotorula

28,85

Fusarium

24,04

Monilia

17,31

16,35

Curvularia

10,58

Trichoderma

8,65

Pleiochaeta

Cunninghamella

3,85

Pullularia

3,85

Syncephalastrum $\quad 2,88$

Phialophora 2,88

Mucor 2,88

Acremonium $\quad 1,92$

Helminthosporium $\quad 1,92$

Acremoniella $\quad 1,92$

Humicola 1,92

Rhizopus $\quad 1,92$

Cephalosporium $\quad 0,96$

Cordaria $\quad 0,96$

Paecilomyces $\quad 0,96$

Nigrospora $\quad 0,96$

Levedura preta $\quad 0,96$

Bispora $\quad 0,96$

Hyalodendron $\quad 096$

Phoma $\quad 0,96$

Pithomyces 0,96

Não identificados $\quad 21,65$

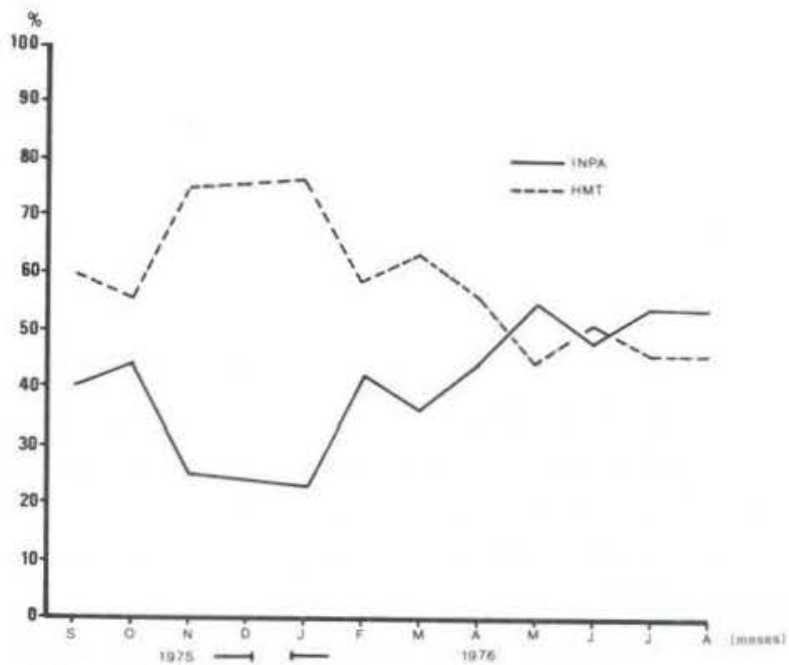

GRAFICO 1 - Fungos no ar e clima 


\begin{tabular}{|c|c|c|c|c|c|c|c|c|c|c|c|c|c|c|}
\hline \multirow[b]{2}{*}{ FUNGOS } & \multirow[b]{2}{*}{ meses $\rightarrow$} & \multicolumn{13}{|c|}{ N. DE COLONIAS } \\
\hline & & Set & Out & Nov & Dez & Jan & Fev & Mar & Abr & Mai & Jun & Jul & Ago & Total \\
\hline \multicolumn{2}{|l|}{ Cladosporium } & 111 & 69 & 14 & 53 & 48 & 23 & 12 & 17 & 7 & 6 & 11 & 34 & 411 \\
\hline \multicolumn{2}{|l|}{ Leveduras brancas } & 27 & 15 & 32 & 24 & 20 & 6 & 11 & 6 & 6 & 2 & 11 & 5 & 165 \\
\hline \multicolumn{2}{|l|}{ Penicillium } & 20 & 14 & 14 & - & 10 & 11 & 1 & 19 & 12 & 14 & 1 & 4 & 120 \\
\hline \multicolumn{2}{|l|}{ Aspergillus } & 6 & 13 & 9 & - & 1 & 2 & 6 & 20 & 2 & 4 & - & 7 & 70 \\
\hline \multicolumn{2}{|l|}{ Fusarium } & 19 & 20 & 1 & - & - & 2 & 1 & 2 & - & 1 & - & 3 & 49 \\
\hline \multicolumn{2}{|l|}{ Rhodotorula } & 13 & 7 & 4 & 3 & 4 & 1 & 3 & - & 1 & 5 & 2 & 1 & 44 \\
\hline \multicolumn{2}{|l|}{ Monilia } & 5 & 1 & 3 & 2 & - & 1 & - & 1 & 7 & - & 5 & 19 & 44 \\
\hline \multicolumn{2}{|l|}{ Curvularia } & 3 & 17 & $\rightarrow$ & $\rightarrow$ & - & - & 1 & - & 3 & 2 & $\rightarrow$ & - & 26 \\
\hline \multicolumn{2}{|l|}{ Trichoderma } & 1 & 4 & 1 & $\rightarrow$ & 一 & - & 1 & 7 & - & 4 & 一 & $\rightarrow$ & 18 \\
\hline \multicolumn{2}{|l|}{ Phialophora } & 4 & - & $\rightarrow$ & - & - & - & - & 10 & - & - & 一 & - & 14 \\
\hline \multicolumn{2}{|l|}{ Mucor } & - & 一 & - & - & - & 1 & 一 & - & - & 7 & 一 & 1 & g \\
\hline \multicolumn{2}{|l|}{ Cunninghamella } & 6 & 一 & - & - & - & - & - & - & 2 & 一 & 一 & 1 & $\mathbf{9}$ \\
\hline \multicolumn{2}{|l|}{ Pleiochaeta } & 5 & 3 & - & - & - & - & - & - & - & 一 & 一 & - & 8 \\
\hline \multicolumn{2}{|l|}{ Syncephalastrum } & - & - & $\rightarrow$ & - & - & - & - & - & 7 & 1 & 一 & - & 8 \\
\hline \multicolumn{2}{|l|}{ Cordaria } & - & 7 & - & - & - & - & - & - & - & - & - & - & 7 \\
\hline \multicolumn{2}{|l|}{ Acremonium } & 3 & 2 & - & - & - & - & - & - & - & - & - & - & 5 \\
\hline \multicolumn{2}{|l|}{ Pullularia } & - & 1 & - & - & 1 & 2 & - & - & - & 1 & - & - & 5 \\
\hline \multicolumn{2}{|l|}{ Helminthosporium } & - & 4 & - & - & - & - & - & - & - & - & - & - & 4 \\
\hline \multicolumn{2}{|l|}{ Acremoniella } & 2 & 1 & - & - & - & - & - & - & - & - & - & - & 3 \\
\hline \multicolumn{2}{|l|}{ Paecilomyces } & - & 3 & $\rightarrow$ & - & - & 一 & 一 & - & 一 & - & 一 & - & 3 \\
\hline \multicolumn{2}{|l|}{ Humicola } & 1 & 1 & - & - & - & - & - & - & - & - & - & - & 2 \\
\hline \multicolumn{2}{|l|}{ Nigrospora } & - & 2 & - & - & - & - & - & - & - & - & - & - & 2 \\
\hline Levedura preta & & 2 & - & - & - & - & - & 一 & - & - & - & - & - & 2 \\
\hline Rhizopus & & - & - & 1 & - & - & - & - & - & - & - & 1 & - & 2 \\
\hline Cephalosporium & & 1 & - & - & - & - & - & - & - & - & - & - & - & 1 \\
\hline Hyalodendron & & $\rightarrow$ & 1 & - & - & - & - & - & - & - & - & - & - & 1 \\
\hline Phoma & & - & 1 & - & $\rightarrow$ & - & - & - & - & - & - & - & $\rightarrow$ & 1 \\
\hline Pithomyces & & 1 & $\rightarrow$ & - & - & - & - & - & - & - & - & - & - & 1 \\
\hline Bispora & & 1 & - & 一 & $\rightarrow$ & - & - & - & - & - & - & 一 & - & 1 \\
\hline Näo identificados & & 17 & 18 & 4 & - & 8 & - & - & 6 & 5 & - & 2 & $\rightarrow$ & 60 \\
\hline TOTAL & & 254 & 204 & 83 & 82 & 92 & 49 & 36 & 88 & 52 & 47 & 33 & 75 & 1.095 \\
\hline
\end{tabular}



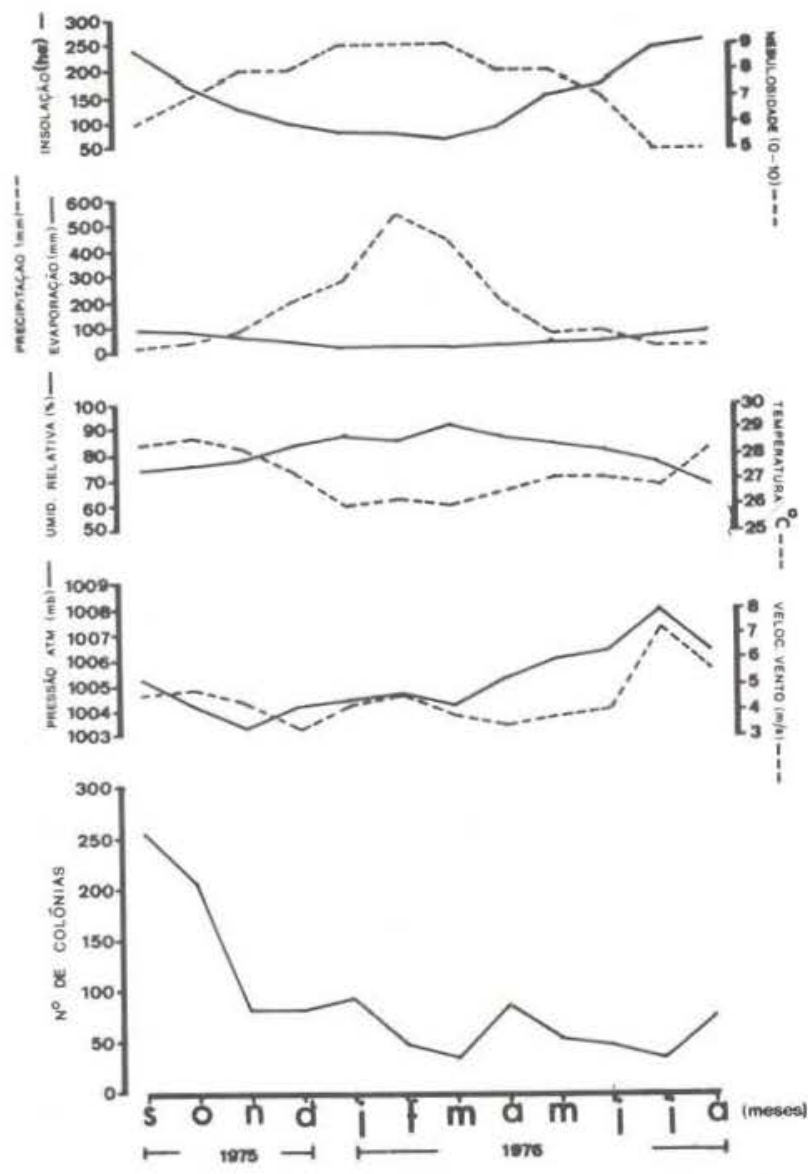

GRAFICO 2 - Diferença (\%) na freqüência de funges nos dois locais de coleta.

\section{COMENTÁRIos E CONCLUSÕES}

Os resultados obtidos mostram, no período estudado, uma freqüência nitidamente predominante do gênero Cladosporium $(37,53 \%)$ sobre os demais fungos.

Essa maior ocorrência se deve. principalmente, ao grande número de colônias desse eumiceto isoladas nos meses de setembro, outubro e dezembro de 1975 e janeiro de 1976 , cujo número perfaz $26,21 \%$ de todos os fungos isolados durante um ano. Além disso, nesses quatro meses foram isoladas $69,82 \%$ das 411 colonias de Cladosporium encontradas nos doze meses de trabalho.

Por outro lado esse gênero tem sido relatado com prêsença significativa nas oito cidades brasileiras estudadas, embora só seja o de maior freqüência nos levantamentos reali- zados em São Paulo (Almeida \& Fava Netto, 1947) e em Belo Horizonte no ano de 1965 (Faria, 1967).

Em Recife, Alecrim \& Teixeira (1958) não registram a presença desse gênero, mas um estudo posterior feito por Coutinho \& Batista (1961), nessa mesma cidade, assinala Cladosporium como o quinto gênero em freqüência por número de exposições no ar dessa cidade nordestina.

Um outro resultado a comentar é a alta precipitação de fungos nos meses de setembro e outubro (Tabela III), tanto qualitativa quanto quantitativamente. Em setembro foram isoladas 254 colônias de 19 gêneros, mais 17 fungos não identificados e, em outubro, 204 colônias de 20 gêneros, mais 15 năo identificados. Esses dois meses percentuam $41,83 \%$ das 1095 colônias estudadas durante um ano de coleta. A explicação para o fenômeno não pode ser encontrada. É possível que pequenas variaçJes climáticas ou conjunto delas, cuja percepção escapou da observação, e que não se repetiram nos outros meses do ano, sejam as responsáveis pelo processo.

O Gráfico 1 que mostra comparativamente as variações mensais de alguns fatores meteorológicos relacionados com o número de colônias fúngicas isoladas, mês a mês, não permite perceber claramente uma correlação fungo-ambiente, embora seja de notar um decréscimo de incidência durante os meses chuvosos.

O fato de o número de fungos totais isolados ter sido maior no Hospital de Moléstias Tropicais (HMT) do que no Instituto Nacional de Pesquisas da Amazônia (INPA) - 59,82\% e $40,18 \%$, respectivamente (Gráfico 2), pode ser justificado pela direção predominante dos ventos (NE). As camadas de ar antes de chegarem ao "campus" do INPA atravessam uma região ainda com cobertura vegetal (floresta), o mesmo não acontecendo no HMT, onde os ventos dominantes atravessam uma vasta área desmatada antes de chegar ao local onde foi realizada a coleta.

Do ponto de vista numérico, isto é, quantidade de esporos e/ou fragmentos hifais no ar, apenas Cladosporium, Leveduras brancas 
e Penicillium nos parecem signifi,a ivos (Tab. I). No aspecto de freqüência por número de exposiçōes, poderiam ser incluídos mais os gêneros Aspergillus, Rhodotorula, Fusarium, Monilia e Curvularia. Esses últimos, embora tenham aparecido com menor incidência, têm uma frequeência anual relativamente grande. Teriam, então, importância do ponto de vista alergênico.

De qualquer forma parece difícil analisar a variação dos resultados em função dos fatores ambientais. A contribuição deste levantamento é então situar a qualidade aerosporológica do ar da cidade de Manaus antes que um parque industrial poluente se instale, ao mesmo tempo em que visa fornecer subsídios etiopatogênicos a alergistas, além de fixar, pela primeira vez, dados sobre a flora fúngica anemófila de um centro urbano da Amazônia Central.

\section{SUMMARY}

Results of a survey of the airborn fungi th Manaus, State of Amazonas, Brazil, are presented. Samples were taken from two different localities of this city during the months of September 1975 through August 1976. The findings are presented in coordination with the seasonal climatological variations and compared with similar studies carried out in other cities of Brazil.

\section{BIBLIOGRAFIA CITADA}

Alecrim, I. \& TeIXeIrA, H.

1958 - Fungos anemófilos na cidade do Recife, Pernambuco Brasil. An. Fac. Med Univ. Recife, $18: 269-274$.

Almeida, F.P. \& Fava Netto, C.

1947 - Observações sobre a flora micológica do ar na cidade de São Paulo. Fich. Terap. Labofarma, $9: 1-3$.

Coutinho, A. \& Batista, C.

1961 - Estudo de aerosporologia na cidade do Recife. I Congresso Soc. Invest. Alergia e Imunopat. Brasil, São Paulo, 5-7 de outubro.

FARIA, A

1967 - Estudo preliminar sobre a flora micó tica anemofila da cidade de Belo Horizonte, Minas Gerais. I - Frequência dos gêneros de fungos de interesse alér. gico. Rev. Inst. Med. Trop., Sāo Paulo, $9: 43-45$

GREGORY, P.H.

1961 - Microbiology of the atmosphere. John Wiley \& Sons, New York.

Mendes, E. \& Lacaz, C. DA S.

1970 - Fungos e alergia. In Lacaz, C. da S. et al. - O Grande Mundo dos Fungos. Poligono \& Ed. Univ. São Paulo, São Pau10.

1972 - Processos alérgicos e geografia médica. In Lacaz, C. da S. et al. - Introdução à Geografia Médica do Brasil. Ed. Blücher \& Ed. Univ. São Paulo, São Paulo. 